\title{
Juventudes: contínuo recomeço e a persistência da vida \\ (Medellin, 2)
}

Rosemary Fernandes da Costa ${ }^{1}$

Pensar sobre as juventudes em nosso tempo histórico é acolher a convocação para uma revisão profunda de conceitos, características definidoras, e nos abrirmos às novas configurações juvenis e às muitas possibilidades de ser jovem, independente da idade cronológica.

Sim, podemos pensar em juventude a partir de critérios biológicos e também de critérios sociais. Mas é importante nos darmos conta de que este é um conceito construído social e culturalmente de forma bastante diversificada. Neste artigo, nosso convite é compreendermos a noção de juventude a partir de suas múltiplas relações e contextos sociais, e não como uma definição isolada e absoluta.

O senso mais comum costuma situar a juventude cronologicamente, como integrante de uma geração especifica que se relaciona com outras gerações. Contudo, aqui trataremos desta conceituação geracional, mas também dos diferentes modos de vivenciar a juventude na contemporaneidade. Podemos pensar sobre as condições de gênero, raça, classe social, moradia e pertencimento religioso.

Há estudos antropológicos e também no campo da psicologia que irão conferir a identidade juvenil não apenas relacionada a uma faixa etária, mas também a outras características que costumam ser atribuídas à juventude, independente da idade cronológica como, por exemplo, a abertura para novas ideias, a coragem de inovar, a luta por sonhos e ideais.

Outro fator a ser considerado é o contexto no qual o jovem nasce, vive, recebe sua formação, desenvolve suas ideias e escolhas. Ou seja, dependendo do contexto social, econômico, cultural, a

11 Rosemary Fernandes da Costa é doutora em Teologia Sistemático-Pastoral pela PUC-Rio, especialista no tema da MISTAGOGIA, assessora da CRB e CNBB e de comunidades educativas e pastorais, professora da Cultura Religiosa na PUC-Rio. Autora dos livros Mistagogia hoje (2014) e A Mistagogia em Cirilo de Jerusalém (2015), pela Paulus, SP. 
condição de juventude será com características diferenciadas, pois cada um desses fatores é parte da configuração pessoal, influencia, condiciona, informa e forma ideias, comportamentos, visões de mundo, escolhas pessoais e culturais.

Uma das referências fundamentais para a análise deste conceito é o Estatuto da Juventude, sancionado pela presidenta Dilma Rousseff em agosto de 2013. Tornou-se um marco importante na afirmação da proteção do Estado aos jovens, demarcando os aspectos constitucionais a serem considerados nas reflexões, avaliações e planejamentos com relação às juventudes.

Citamos aqui a pesquisadora Tania Mayer, articulista do portal Dom Total:

Em nosso país, "são consideradas jovens as pessoas com idade entre 15 (quinze) e 29 (vinte e nove) anos de idade". (EJ, 2013, art. $\left.1^{\circ}, \S 1^{\circ}\right)$. No entanto, esse mesmo Estatuto destaca que "aos adolescentes com idade entre 15 (quinze) e 18 (dezoito) anos" se aplica o ECA, o Estatuto da Criança e do Adolescente, e o EJ, excepcionalmente, "quando não conflitar com as normas de proteção integral do adolescente". O EJ visa especificar os direitos e as políticas públicas destinadas aos jovens, as quais, embora já sejam previstas pela Constituição, devem ser aprofundadas. (MAYER, 2018)

O EJ afirma que os jovens são "sujeito de direitos universais, geracionais e singulares" (EJ, 2013, seção I, art. 2º, IV). Tania Mayer analisa que, apesar de parecer óbvio, o Estatuto vem proteger os direitos dos jovens e adolescentes, que precisam ser preservados e defendidos pelo Estado. Para a sociedade brasileira, a ideia de juventude, muitas vezes está associada a estudantes, aos jovens empobrecidos, aos negros, aos jovens de baixa renda, às mulheres, aos LGBTs, e estes, não eram protegidos pelas ações afirmativas por parte dos governos e demais instituições. Enfim, o que é compreendido com o direito de cidadania não recebe acolhida e legitimidade de parte da população brasileira, por isso mesmo, explicitar os direitos aparentemente óbvios se faz urgente. (cf. MAYER, 2018)

Chamamos atenção ainda para o nosso lugar epistemológico ao tratar deste tema. Seja o meu lugar, como educadora (há 43 anos) e como teóloga, ou o lugar específico de tantos pesquisadores e assessores das juventudes, precisam ser demarcados aqui no seu olhar epistemológico, que não deixa de ser considerados como 
responsáveis, mas que reconhecem a alteridade e a necessidade de que a própria juventude fale por si mesma, como se compreende, como se identifica, como gerencia os processos diferenciados e, ao mesmo tempo, em busca de participações comuns, na luta por seus sonhos e por seus direitos.

Assim sendo, ao dialogarmos com a diversidade dos grupos juvenis, com suas múltiplas identidades e contextos, compreendemos que o termo - juventudes - é o mais apropriado, pois a característica plural é preservada. Por outro lado, ao tratarmos de juventudes, saímos do campo do conhecimento universal e absoluto, e nos abrimos para as construções dialógicas. Aqui entramos em um tema muito presente nos grupos de juventudes, que diz respeito às subjetividades, sobre o qual trataremos mais adiante.

Em termos de cuidados pastorais, o tema da juventude/juventudes está muito presente nas orientações da Igreja. Podemos retomar, por exemplo, a Conferência de Medellín, ocorrida na Colômbia no período de 24 de agosto a 6 de setembro de 1968: dimensão profética e pedagógica da Igreja. Nas Conclusões de Medellín, encontramos um olhar para os jovens como aqueles que clamam e também que semeiam uma nova sociedade, como um novo corpo social que possui seus próprios valores e sonhos, mas que não são ingênuos com relação às estruturas de desumanização. A lgreja se percebe como pastora, como ouvinte e como aprendiz dessa comunidade juvenil em suas mobilizações na direção a um projeto de transformação social latino-americana.

Ela (a juventude) se apresenta, em grande parte do continente, como um novo corpo social (com perigo de detrimento na relação com os outros corpos sociais), portador de ideias próprias e valores inerentes ao seu próprio dinamismo interno. Procura participar ativamente, assumindo novas responsabilidades e funções, dentro da comunidade latino-americana.(CELAM, Medellín, 1970, 5,1)

As décadas seguintes à Conferência de Medellín foram marcadas por reações da juventude aos governos radicais militares, opressores e coniventes com os sistemas econômicos que trouxeram maior desigualdade e injustiças sociais em todo o país. Através de manifestações políticas e estéticas, a juventude se fez presente, arriscando a própria vida e a liberdade por causas que ultrapassaram a cidadania local, na direção da cidadania global. Da parte dos 
interesses políticos e econômicos, também surgiram reações de opressão, censura e construção de um imaginário social que prometia o bem estar social de todos os povos latino-americanos.

Contudo, desde os anos 70, as Conclusões de Medellín também diagnosticavam diferentes características e atitudes na juventude desse período:

Enquanto um setor da juventude aceita passivamente as formas burguesas da sociedade (deixando-se levar, às vezes, pelo indiferentismo religioso), outro rejeita com marcado radicalismo o mundo que seus pais construíram, por considerar seu estilo de vida carente de autenticidade; rejeita igualmente uma sociedade de consumo que massifica e desumaniza o homem. Esta insatisfação cresce de momento a momento. (CELAM, Medellín 5, 1.3)

Quando o documento de Medellín convoca a comunidade latino-americana a reagir na busca da posse de sua autorrealização pelo serviço e no amor, ele faz alusão ao eixo referencial da juventude. A emergência da convocação tem como fundamento a percepção enraizada e consciente da juventude.

(...)já soou a hora para nossos povos de descobrirem seu próprio ser, pleno de originalidade; está orientada no sentido de sustentar uma economia baseada na ânsia de «ter mais», quando a juventude latino-americana exige "ser mais", na posse de sua autorrealização pelo serviço e no amor. (CELAM, Medellín 4,1)

Os jovens são mais sensíveis do que os adultos aos valores positivos do processo de secularização. Esforçam-se por construir um mundo mais comunitário, que vislumbram, talvez, com mais clareza do que os antepassados. Estão mais abertos a uma sociedade pluralista e a uma dimensão mais universal da fraternidade.(CELAM, Medellín 4,1.4)

A Conferência de Medellín propõe projeto, trajetória. Enfim, se concebe como impulso pastoral e ético, e também pedagógico e histórico. Por isso mesmo, a juventude ecoa no chão latino-americano seus sonhos, lutas e inquietudes. A juventude nos fala de esperança, de resgate dos sonhos, de ousadia e identidade, de trincheiras conscientes e firmes em sua vocação profética.

Em continuidade ao diálogo entre a lgreja e o mundo, na Exortação Apostólica Evangelii Gaudium, o papa Francisco nos diz: “Constituamo-nos em 'estado permanente de missão' em todas as regiões da terra" (EG, 25). Francisco dá uma atenção especial à 
juventude: "A Pastoral Juvenil, tal como estávamos acostumados a desenvolvê-la, sofreu o impacto das mudanças sociais... A nós adultos custa-nos a ouvi-los com paciência, compreender as suas preocupações ou as suas reivindicações, e aprender a falar-lhes a linguagem que eles entendem" (EG,105).

É ainda o Papa Francisco, na Encíclica Laudato Si, quem nos orienta à dimensão da ética global e, falando de educar para a aliança entre humanidade e o ambiente, afirma: "Os jovens têm uma nova sensibilidade ecológica e espírito generoso, e alguns deles lutam admiravelmente pela defesa do meio ambiente" (LS, 209).

Em 2017, Francisco convocou uma Assembleia Geral Ordinária do Sínodo dos Bispos para outubro de 2018 com o tema "Os Jovens, a fé e o discernimento vocacional". No documento preparatório ele escreve uma Carta aos jovens animando a que acolham o convite do Senhor para ir e promover uma "terra nova", "uma sociedade mais justa e fraterna": "Aquele grito nasce do vosso coração jovem, que não suporta a injustiça e não pode inclinar-se à cultura do descarte, nem ceder à globalização da indiferença".

O sínodo foi construído de forma participativa, com documento preparatório e a solicitação de que toda a comunidade católica mundial se debruçasse sobre as questões propostas através do questionário disponibilizado no documento como também de palestras, rodas de conversa, círculos bíblicos, avaliações pastorais. Não foi, portanto, construído sem a participação dos protagonistas do tema e sim uma abertura para um diálogo verdadeiro, fraterno, empenhado em integrar a fé e a vida, como seguidores do mestre Jesus.

O Documento final consta de três partes que tem por fundamento a passagem do Evangelho de Lucas sobre os discípulos de Emaús: "caminhava com eles", "eles abriram os olhos" e "partiram sem demora". Na primeira parte - "caminhava com eles" -, o documento apresenta o contexto no qual as juventudes estão inseridas e aqui o tema da "escuta" é fundamental. Como dissemos acima, a dimensão dialógica é fundamental nas reflexões sobre as juventudes, e esta atitude é fundamental para a aproximação a cada contexto, identidades e possibilidades de participação na vida pastoral e na cidadania comunitária e global. Esse é o foco da segunda parte - "eles abriram os olhos" -, reforça o olhar de valorização das juventudes e de seu dinamismo renovador. Na terceira parte - 
"partiram sem demora" -, as orientações apontam para a perspectiva missionária e para a formação e discernimento a cada realidade.

Desejamos aqui destacar o foco na "escuta" tão lindamente trabalhada no documento final.

A escuta é um encontro de liberdades, que exige humildade, paciência, disponibilidade para compreender, esforço por elaborar de maneira nova as respostas. A escuta transforma o coração daqueles que a vivem, principalmente quando se colocam em atitude interior de sintonia e docilidade ao Espírito. Por conseguinte, não é somente um recolher de informações, nem uma estratégia para alcançar um objetivo, mas representa a forma como o próprio Deus Se relaciona com o seu povo. Com efeito, Deus vê a miséria do seu povo e escuta a sua lamentação, deixa-Se tocar intimamente e desce para o libertar (cf. Ex3, 7-8). Portanto, através da escuta, a Igreja entra no movimento de Deus que, no Filho, vem ao encontro de cada ser humano. (SJ 6)

Esta atitude pede uma nova dinâmica nos planejamentos, não mais demarcados pela concepção de individualidade, e sim na subjetividade relacional, fruto das estruturas dialógicas. Trata-se da concepção de pessoa como um texto aberto, plural, capaz de muitas vozes, novos acordos, novos significados. É a prática de subjetividades abertas, construídas a partir das relações, nas quais cada pessoa recebe a alteridade e é constituída a partir das muitas subjetividades.

Esta atitude apresentada como fundamental no Documento do Sínodo já se encontra nos encontros juvenis, sejam em grupos unidos por causas políticas, sociais ou de cunho religioso, ou mesmo integrando todas essas dimensões fundamentais da vida. Nos encontros são garantidas as estruturas dialógicas, abertas, acolhedoras das diferenças de ideias, credos, gêneros, posicionamentos filosóficos, econômicos e políticos. A estrutura intersubjetiva considera as identidades em sua originalidade, em diálogo aberto, escuta ativa, acolhedora e também interpelante. As narrativas pessoais são consideradas parte da construção dos projetos, as estratégias e decisões são processuais, flexíveis, abertas a avaliação e revisões constantes.

Neste novo campo relacional, a proximidade é um dos eixos. Ao contrário do individualismo arraigado nos espaços sociais, as juventudes vivenciam o dinamismo relacional com todos os seus 
desafios e possibilidades. Experimentam as próprias limitações, a negação do individualismo e a corresponsabilidade. É um campo novo para culturas nas quais as pessoas se percebem de forma solitária e distanciadas. Na dinâmica das intersubjetividades somos interpelados a construir aproximações: de significados e representações, de linguagem, de identidades e pertenças, de visões de mundo.

Enfim, é uma mudança paradigmática em gestação e já dando seus frutos fecundos que modificam os projetos, os planejamentos, a própria percepção pessoal, comunitária e de mundo. No entanto, para o Cristianismo, não estamos exatamente falando de uma mudança de paradigma ou de uma novidade epistemológica e sim do resgate do centramento vital cristão, no encontro com o outro, na relação dialógica, para a experiência do crer que se traduz em amor, como lembra a epístola joanina - "Amemo-nos uns aos outros, pois o amor vem de Deus; e todo aquele que ama nasceu de Deus e chega ao conhecimento de Deus. Quem não ama não descobriu a Deus, porque Deus é amor". (1Jo 4,7) Só a experiência do amor é capaz de superar a aporia do conhecimento sem amor.

Um segundo ponto que desejamos destacar no Documento final do Sínodo das Juventudes é a consideração da vulnerabilidade a que as juventudes estão expostas em seus diferentes contextos.

O Sínodo, em sua dimensão profética e pedagógica não apenas 'escuta' os contextos particulares, comunitários e globais, mas também, assume o discernimento e as orientações para a transformação das estruturas que não corroboram para a justiça, a fraternidade e a dignidade das juventudes.

Muitos jovens vivem em contextos de guerra e são vítimas da violência numa incalculável variedade de formas: raptos, extorsões, crime organizado, tráfico de seres humanos, escravidão e exploração sexual, estupros de guerra, etc. Outros jovens, em virtude da sua fé, têm dificuldade de encontrar um lugar nas respectivas sociedades e padecem vários tipos de perseguição, que vai até à morte. São numerosos os jovens que, por constrangimento ou por falta de alternativas, vivem perpetrando crimes e violências: crianças-soldado, grupos armados e criminosos, tráfico de droga, terrorismo, etc. Esta violência ceifa inúmeras jovens vidas. Abusos e dependências, assim como violência e perversão contam-se entre as razões que levam os jovens à prisão, com uma incidência particular sobre alguns grupos étnicos e sociais. Todas estas situações questionam e interpelam a Igreja. (SJ, 41) 
Em terras brasileiras, temos vivenciado tempos em que o resgate da cidadania é clamor, é exercício cotidiano e convocação do mais profundo do ser pessoa. Podemos constatar que nesse resgate as juventudes estão abraçando um conceito de cidadania do mundo, que integra duas instâncias: o exercício político local da comunidade civil, para conviver de forma organizada, digna e pacífica, com a garantia de um mínimo de valores para todos e para cada pessoa, e uma segunda instância, como diálogo com a identidade de cada homem e de cada mulher, como membros da grande comunidade humana e sociocósmica. São juventudes que acolhem o grito da terra, dos povos, sentem o grito dos corpos, das vidas escravizadas e as dinâmicas que promovem desigualdades de tantas dimensões, e se deixam fecundar e transformar, e devolvem com voz, mãos, passos, a luta pela vida para todos e todas, para toda a Criação, para todo o Cosmos.

Concluímos com as palavras do Documento do Sínodo, como chamado à vocação profunda de todo ser humano e à dinâmica confiante, na graça que nos conduz e sustenta nesse caminhar que é de todos e de todas, sem acepção de pessoas.

Uma Igreja sinodal e missionária manifesta-se através de comunidades locais habitadas por muitos rostos. Desde os primórdios, a Igreja não adotou uma forma rígida e homologante, mas desenvolveu-se como um poliedro de pessoas com sensibilidades, proveniências e culturas diferentes.A harmonia, que é o dom do Espírito, não suprime as diferenças, mas concilia-as gerando uma riqueza sinfônica. Diz a sabedoria popular que "é preciso uma aldeia inteira para educar uma criança". (SJ 131)

\section{REFERÊNCIAS:}

CONFERÊNCIA GERAL DO EPISCOPADO LATINO-AMERICANO. Conclusões de Medellín. São Paulo: Paulinas, 1970.

CONFERÊNCIA NACIONAL DOS BISPOS DO BRASIL. Evangelização da juventude: desafios e perspectivas pastorais. São Paulo: Paulinas, 2007 (Documentos da CNBB, 85).

COSTA, Rosemary Fernandes. A opção pelos jovens e o caminho das juventudes no século XXI. In: SOUZA, N. e SBARDELOTTI, E. 
Medellín. Memória, profetismo e esperança na América Latina. Petrópolis: Vozes, 2018.

MAYER, Tania da Silva. As juventudes que querem vida. Vida Pastoral, 2018. Disponível em http://www.ofm.org.br/artigo/asjuventudes-querem-vida-18062018-140049, acesso 14 de fevereiro de 2019

PAPA FRANCISCO. Exortação Apostólica Evangelii Gaudium. São Paulo: Paulus/ Loyola, 2013

PAPA FRANCISCO. Carta Encíclica Laudato Si. Sobre o cuidado da casa comum. Vaticano: Libreria Editrice Vaticana, 2015. Disponível em: http://w2.vatican.va, acesso em 15 de fevereiro de 2019.

PAPA FRANCISCO. SÍNODO DOS BISPOS. Os jovens, a fé e o discernimento vocacional: documento preparatório da XV Assembleia do Sínodo dos Bispos. São Paulo: Paulus, 2017.

PEREIRA, Alexandre Barbosa. Juventude, juventudes. São Paulo: Fundação Perseu Abramo. Disponível em: https://fpabramo.org.br/2012/04/20/juventude-juventudes/, acesso a 15 de fevereiro de 2019.

\section{PROPOSTA PARA REFLEXÃO:}

1. Assistir ao vídeo sobre a entrega da Carta aos Jovens, em preparação para o Sínodo das Juventudes https://www.youtube.com/watch?v=nVq7aFqYnoM

2. Quais os principais os eixos para pensar as juventudes hoje?

3. Como as juventudes, em sua diversidade, poderiam se integrar nas causas comuns? 